\title{
NIGHT VISUAL CAPACITY OF NEUROTIC SOLDIERS
}

\author{
BY
}

\section{W. LINFORD REES}

\author{
(RECEIVED 22ND MARCH, 1945)
}

NigHT blindness has been known since the time of the ancient Egyptians and was described by Hippocrates in the second book of Prorrhetics. One thousand years after Hippocrates, the beneficial effects of liver on night blindness were described by the Byzantine physician Paulus Aegineta. Rhazes recognized no less than three varieties (Holcomb, 1934). Richerand described an unrecognized occupational neurosis in the eighteenth century marked by night blindness and photophobia, caused by exposure to intense illumination (Culpin, 1940). The study of night vision, though always of interest, is of greater practical importance in war time, in view of black-out conditions, night driving, and night operations.

The ability to see in diminished illumination shows considerable individual variation. Minor degrees of night blindness are common. Maitra and Harris (1937) found that of 200 poor-class children, 20-30 per cent. were slightly below normal and 20-30 per cent. definitely subnormal in dark adaptation. Bishop Harman (1941) found that 14-28 per cent. of the normal population see poorly at night, the percentage increasing with age. Rycroft (1942) reported that $7-14$ per cent. of four regiments tested were night vision defective. Lister and Bishop (1943) found that 3.9 per cent. of 10,333 first-class soldiers had poor scotopic vision.

Night blìndness may be due to pathological eye changes, congenital and hereditary causes, vitamin A deficiency, pathological changes in liver, or overexposure to light, Duke Elder (1938). Deficiency of vitamin $A$ is the most widely accepted cause for defective night vision, and because of this it is estimated by dark adaptation tests, Harris and Abbasy (1939). Jeans and Zentmire (1934) produced normal dark adaptation by the administration of vitamin $A$ in the majority of a group of children suffering from defective dark adaptation, and similar results were also obtained by Schuck and Miller (1938).

Some cases of night blindness have no apparent pathological or nutritional causes, and a number of writers have described hysterical or neurotic types. H. Smith (1921) regarded night blindness as malingering and postponed the publication of his paper until the end of the War, so as not to aid the enemy, who were discharging large numbers of men for the condition. Derby (1921) described "epidemics" of night blindness in the last war; Duke Elder (1938) pointed out that most patients without pathological changes or nutritional disturbances have neurasthenic and other functional symptoms also, while Livingston and Bolton (1943) suggest that some of the variations in night visual capacity recorded in healthy people may depend on differences in mental make-up. Wittkower, Rodger, et al. (1941) in a study of 52 soldiers complaining of night blindness found that the majority were suffering from severe psychological disorders. Over a half gave a history of over-dependence, neurotic traits, morbid fears, and excessive fear of darkness; while fears of injury (especially to the eye) were commonly seen and long antedated the onset of the disorder. Livingston and Bolton (1943), in an investigation of 50 patients suffering from neurosis, found that those with anxiety states performed the night visual capacity test poorly, whereas depressives and obsessionals gave satisfactory scores.

The purpose of this present study is primarily to determine whether a random sample of soldiers suffering from neurosis differed significantly in night visual capacity from normal control groups; secondarily whether the various neurotic types differed significantly from each other; and finally to find what characteristics or traits, if any, are associated with poor and good night vision.

\section{The Material}

The experimental population consisted of 96 soldiers (other ranks) suffering from clearly defined neurotic syndromes successively admitted to Mill Hill Emergency Hospital. Cases with mixed types of neurosis were rejected in order to facilitate the interpretation of the results. They were unselected regarding night visual capacity, and the psychiatric diagnosis was made by trained psychiatrists before testing, so that the subjective factor in their selection was reduced to a minimum.

The total group consisted of 36 men suffering from anxiety states, 33 men with depressive states, and 27 hysterics. They were all on full hospital diet, and none suffered from any marked visual defects.

\section{The Technique}

The men were tested by means of the Livingston Rotating Hexagon, an apparatus primarily designed for testing night visual capacity of R.A.F. personnel. The test was carried out by a W.A.A.F. Officer who was a trained Orthoptist and experienced in the use of the 
apparatus. The test procedure was exactly the same as that used in testing R.A.F. personnel. A detailed description of the use of the Hexagon is given by Livingston (1942). Described briefly, the hexagon, which can be rotated so as to present different panels to the subject tested, has 96 letters and objects distributed on its 6 sides. The letters are placed in various positions, and the objects are in forms of aircraft, ships, parallel lines, etc. Preparation for the test includes 30 minutes dark adaptation, with dark goggles, only admitting 3 per cent. light, followed by 10 minutes in the dark room during which the details of the test are carefully explained. That this is an adequate period of dark adaptation is confirmed by the experiments of Yudkin (1943) who found that though 15 minutes, the time used in some tests, was inadequate, there was no improvement in dark adaptation after 35 minutes with the various types of apparatus tested. The subject is able to record his interpretation of the objects and letters in the dark by means of special Braille cards.

Four routine tests are given at different levels of illumination, each concerned with 6 letters and 2 objects, giving a total of 32 . In each test a minute is allowed to record the answers with due warning after 45 seconds. A fifth test can also be given to detect any possible malingerers, or patients with hysterical amblyopia. In this, 3 large capital letters are exposed against a background sufficiently illuminated to ensure that they would be easily discernible except by those suffering from advanced pathological conditions, (Livingston and Bolton 1943).

During the explanation of the test the patients were encouraged to do as well as possible and to compete with each other, and told that they would be able to see the objects more clearly if they gazed a little to the side of the object. In order to allay any suspicions about the test, it was carefully pointed out that it was a scientific investigation, and was not in any way relevant to their treatment or disposal.

Lythgoe (1940) stresses the dual mechanism of dark adaptation. The first part of the process lasts 6-11 minutes and is concerned with the adaptation of the photopic mechanism of vision. The second phase is the adaptation of the scotopic mechanism mediated by the retinal rods and their visual purple. Visual sensitivity during dark adaptation may increase 10,000 times.

The Livingston Rotating Hexagon test examines a mixture of rod and cone vision, the background brightness during the test ranging from $0 \cdot 00015$ eq. $\mathrm{ft}$. candles to 0.0012 eq. $\mathrm{ft}$. candles. Each apparatus is calibrated by a skilled technician in photometry to ensure that the light values of each apparatus are comparable.

\section{Results}

The results of the total group of 96 men are shown in the frequency histogram, Fig. 1. Fig. 2 shows the results of night visual capacity testing of 6,062 R.A.F. personnel with the Rotating Hexagon,

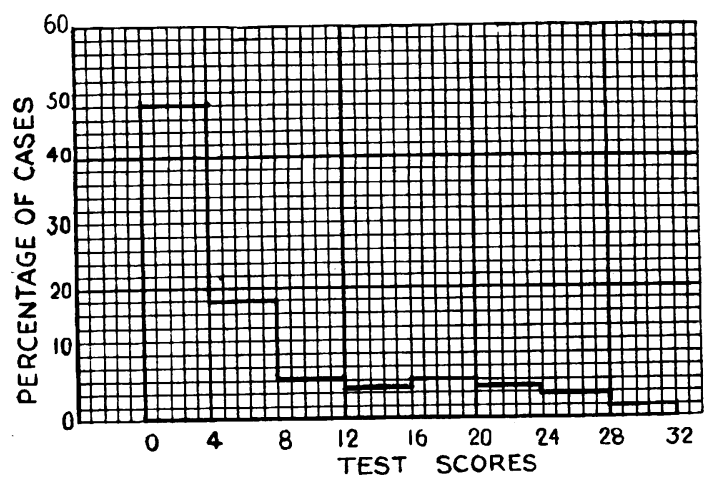

FIG. 1.

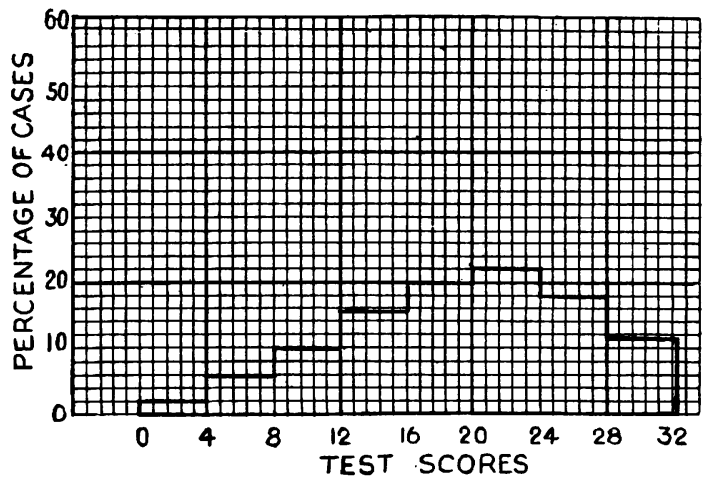

FIG. 2.

which were kindly supplied by Air Commodore Livingston.

It will be seen that whereas the results of the R.A.F. personnel group are distributed in a normal frequency or Gaussian curve, the frequency distribution of the neurotic group is in the form of a reversed " $\mathrm{J}$ "-shaped curve.

Inspection of the two frequency distributions indicates that the performance of the neurotic group on the test is markedly inferior to that of the R.A.F. group. This impression is confirmed by statistical comparison of the means. The mean night visual capacity of the R.A.F. group is $19 \cdot 32$, standard deviation 3.5 , that of the neurotic group is $7 \cdot 1$, with a standard deviation of $8 \cdot 05$. The difference between the means is highly significant statistically (critical ratio $=14 \cdot 84$ ). The Median of the neurotic group is 4.0 and the values of the 25 th and 76th percentiles 1.92 and 12.0 respectively. The corresponding figures for the R.A.F. group are $18 \cdot 99,14 \cdot 48$, and $24 \cdot 8$. In view of the dissimilarity between the two frequency distributions the chi square test was also applied. $\mathrm{X}^{2}$ was found to be 984.48 ( $\mathrm{P}=$ considerably less than 0.01$)$, which again indicates that the difference between the two groups is of high statistical significance.

We conclude, therefore, that the performance of the neurotic group on the test is significantly inferior to that of the R.A.F. group.

\section{Neurotic types}

Table I shows the results obtained by the various types of neurosis.

TABLE 1

\begin{tabular}{l|c|c|c|c|c|c|c}
\hline & \multirow{2}{*}{$\begin{array}{c}\text { No. } \\
\text { of } \\
\text { Type }\end{array}$} & \multicolumn{3}{|c|}{ Test score } & & Mean \\
\cline { 3 - 6 } & cases & $0-7$ & $8-15$ & $16-23$ & $24-32$ & Me- \\
dian
\end{tabular}


Anxiety State Group.-Eleven men of this group complained that they were unable to make out any letters or objects though some had obtained a few marks. These men were tested with the top panel with bright illumination in order to discover malingerers or hysterics, one man only gave a result suggestive of malingering or hysteria. The group is significantly inferior in performance on the test to the R.A.F. group. $\left(\mathrm{X}^{2}=512 \cdot 6, \mathrm{P}\right.$ is considerably less than 0.01.)

Depressive State Group.-Five of this group of 33 subjects complained that they were unable to see anything. They were tested with the top panel but none gave the hysterical or malingering response. The results are somewhat better than those of the Anxiety State Group but the difference is not statistically significant $\left(\mathrm{X}^{2}=1 \cdot 42\right.$. $\left.\mathrm{P}=0.99\right)$. The performance of the group is significantly inferior to that of the R.A.F. Group. $\left(X^{2}=177 \cdot 9\right.$. $P$ is less than 0.01.)

Hysteria Group.-Eight of the group of 27 hysterics complained that they were unable to make out the objects and letters. These men were accordingly tested with the top panel, but none gave the malingering or hysterical result. The performance of the group in the test is somewhat better than that of the Anxiety State and Depressive State Groups, but the differences are not statistically significant. (Hysteria and Anxiety State $\mathrm{X}^{2}=8 \cdot 36$. P is between $\mathbf{0 . 2}$ and 0.31 . Hysteria and Depressive State, $\mathrm{X}^{2}=1 \cdot 69$. $\quad \mathrm{P}=\mathbf{0} \cdot 97$.)

\section{Comparison with other Normal Groups}

The group of 6,062 R.A.F. personnel is not ideal as a control group, as the standards for enlistment in the R.A.F. are more rigorous than for the Army, so that the R.A.F. results may be higher than those of the general population of the British Isles. Unfortunately data for results of the test on the general population are not available. Steadman (1942) tested men of an Anti-Aircraft Battery with the Livingston Rotating Hexagon, and the percentage results obtained are given in Table II, together with data on 2,000 R.A.F. personnel. Steadman graded the results as follows:-

\begin{tabular}{|c|c|c|}
\hline Exceptional & $29-32$ & Below average \\
\hline $\begin{array}{l}\text { Above average } \\
\text { Average } \quad . .\end{array}$ & $\begin{array}{r}20-28 \\
9-19\end{array}$ & Poor $\quad$. \\
\hline
\end{tabular}

The neurotic groups were graded similarly and the percentage distribution is shown in Table II.
The results shown in the table confirm our previous conclusions and show in a striking manner the weighting of the total neurotic group, and component neurotic groups towards the lower end of the scale of night visual capacity.

Age Factor.-That night vision becomes worse with increasing age has been shown by Ferree et al. (1935 and 1938), Bishop Harman (1941), Rycroft (1942), and Lister and Bishop (1943). It is therefore important to determine whether the age factor has a significant influence on our results. The mean age of the total group is 30.2 years, standard deviation $6 \cdot 6$. The product moment correlation between age and night visual capacity test score for the total group was found to be -0.394 \pm 0.086 . This negative correlation is statistically significant and indicates that the older age groups tend to have poorer night visual capacity. The mean age of those performing well on the test (19 and over) is 27.6 years, standard deviation 6.04 , and that of the group performing very poorly ( 4 and under) was $32 \cdot 2$ years, standard deviation $7 \cdot 04$. The difference of low statistical significance (critical ratio $=2$ ). Thus there is a definite association between age and score on the test. Lister and Bishop (1943), however, found that using the Army night vision test on 10,333 soldiers, there was a steady fall in night visual capacity from the age of 18 , but that the fall between 18 and 44 was so slight as to be of little practical importance.

\section{Intelligence Factor}

Rycroft (1942) states that intelligence plays a part in the results of night vision test results, the more intelligent tending to do better. In order to test the possible influence of intelligence on the results, each man was given Raven's Progressive Matrices Group Intelligence Test, and the results were graded in the usual way into five grades, grade 1 indicating superior intelligence and grade 5 poor intelligence. The Pearson product moment correlation coefficient was calculated for night visual capacity score and Matrices grade, and was found to be $r=0 \cdot 107 \pm 0 \cdot 1$. The correlation is only slightly greater than its standard error, and is not statistically significant. The Mean Matrices grade for the total group was 2.69 (standard deviation 1.16). As. Grade 3 is the accepted grade of average intelligence, the mean grade of the total neurotic group is somewhat above average intelligence and, therefore,

TABLE 2.

\begin{tabular}{|c|c|c|c|c|c|c|c|c|c|c|}
\hline \multicolumn{4}{|c|}{ Grade } & A.A. men & Officers & R.A.F. & Anxiety & Depressive & Hysteria & $\begin{array}{c}\text { A total } \\
\text { neurotic }\end{array}$ \\
\hline $\begin{array}{l}\text { Exceptional } \\
\text { Above average } \\
\text { Average ... } \\
\text { Below average } \\
\text { Poor ... }\end{array}$ & $\begin{array}{l}\ldots \\
\cdots \\
\cdots \\
\cdots \\
\cdots\end{array}$ & $\begin{array}{l}\cdots \\
\cdots \\
\cdots \\
\cdots\end{array}$ & $\begin{array}{l}. \\
\cdots \\
\cdots \\
\cdots \\
.\end{array}$ & $\begin{array}{r}1 \cdot 4 \\
18 \cdot 2 \\
49 \cdot 1 \\
23 \cdot 1 \\
8 \cdot 2\end{array}$ & $\begin{array}{l}20 \\
26 \cdot 7 \\
53 \cdot 3 \\
0 \\
0\end{array}$ & $\begin{array}{r}3 \cdot 5 \\
32 \cdot 8 \\
49 \cdot 6 \\
13 \cdot 1 \\
1 \cdot 0\end{array}$ & $\begin{array}{l}0 \\
2 \cdot 77 \\
16 \cdot 66 \\
30 \cdot 55 \\
50.0\end{array}$ & $\begin{array}{r}3 \cdot 30 \\
12 \cdot 12 \\
18 \cdot 18 \\
24 \cdot 24 \\
42 \cdot 42\end{array}$ & $\begin{array}{c}3 \cdot 703 \\
14 \cdot 81 \\
18 \cdot 51 \\
25 \cdot 92 \\
37 \cdot 03\end{array}$ & $\begin{array}{c}2 \cdot 83 \\
9 \cdot 375 \\
17 \cdot 17 \\
28 \cdot 12 \\
43 \cdot 75\end{array}$ \\
\hline $\begin{array}{l}\text { Average marks } \\
\text { Number ... }\end{array}$ & $\begin{array}{l}\cdots \\
\cdots\end{array}$ & $\begin{array}{l}\cdots \\
\cdots\end{array}$ & $\begin{array}{l}\cdots \\
\cdots\end{array}$ & $\begin{array}{l}12 \cdot 9 \\
151\end{array}$ & $\begin{array}{l}19 \cdot 6 \\
15\end{array}$ & 2,000 & $\begin{array}{l}4 \cdot 8 \\
36\end{array}$ & $33^{7 \cdot 9}$ & 27 & $\begin{array}{l}7 \cdot 105 \\
96\end{array}$ \\
\hline
\end{tabular}




\section{NIGHT VISUAL CAPACITY OF NEUROTIC SOLDIERS}

we are unable to explain the poor results of the total group on the intelligence factor.

As the extreme ranges of intelligence may have cancelled each other out within the groups, it was decided to compare the intelligence grades of those who had scored poorly (4 and less) with those who had scored well (19 and over).

The results are given in Table III.

From the table it will be seen that in the good night vision group the percentage increases in the "above average" intelligence grades (Grades II and I), whereas, in the poor night vision group, the proportions are normally distributed. Though there are considerable differences in the percentages in the grades indicating a higher intelligence in the good night vision group, the differences are not statistically significant.

In the good night vision group 76.9 per cent. are above average intelligence, whereas, in the poor night vision group only 30 per cent. are above average intelligence. The difference is statistically significant (critical ratio $=2 \cdot 76$ ). Thirty per cent. are below average in poor night vision group, whereas only 7.69 per cent. of the good night vision group are below average intelligence. The difference is statistically significant (critical ratio $=2 \cdot 21$ ). Thus the group with good night vision has a demonstrably higher intelligence as measured by the Matrix test.

\section{Effect of Suggestion on the Test Results}

Nine men who had obtained low scores ( 2 and under) were given a talk in which they were firmly told that better results were expected of them, and strong suggestion was given to the effect that they would improve with retesting.

Seven patients had Anxiety states; of these, one increased his score from 0 to 1 , and another from 1 to $4 ; 3$ men obtained the same scores, and 2 decreased their scores from 1 to 0 , and 2 to 1 . The remaining 2 patients had Depressive states; one patient decreased his score from 3 to 1 , and the other obtained the same score as before. Three men improved their scores, gaining a total of 4 points, and 3 men performed more poorly, losing $\boldsymbol{e}$ total of 4 points, thus, the resultant effect of suggestion was nil. In no case did sufficient improvement occur to promote the patient from the very poor group (scores of 4 and under).
Comparison of Good Night Vision and Poor Night Vision Groups.-In order to determine whether good and poor night vision are associated with characteristic traits, a group of 50 men with poor scores (4 and under) were compared with the group of men (13) who had scored well (19 and over), in respect of over 150 items which had been scored by the physician in charge of the case on a special item sheet before the night vision test was carried out. The percentage distribution of the various items in the two groups was calculated and the significance of the difference determined by means of the Critical Ratio (C.R.).

The following is a brief account of the results.

Social Data.-The proportion of N.C.Os. is higher in the good night vision group ( 30.7 per cent. compared with 16 per cent. in poor group). There were no significant differences in type of service occupation, duration of service, modal civilian occupation and pre-service earnings. Twenty-eight per cent. of the poor group had considerable unemployment compared with nil in good group (C.R. $=4 \cdot 41$ ). Similarly the work history showed unduly frequent changes of occupation in a significantly greater proportion of the poor group (10 per cent. poor group; C.R. $=2 \cdot 37$ ). An indication that the men with poor night vision are on the whole poorer material is given by the fact that 46 per cent. were considered to be of no further use to the Army, and were discharged category "E." This proportion is statistically significantly greater than that of the group with good night vision (15.38 per cent., C.R. $=2 \cdot 43$ ).

Family History.-There was a higher incidence of a family history of neuropathy in the poor group, but the differences were not statistically significant.

Personal History.-Most of the items relating to the personal history revealed a greater incidence of unsatisfactory factors in the poor night vision group. Thirty per cent. of the poor group did not pass standard five at school, and this is a significantly higher percentage than that found in the good night vision $(7.69$ per cent. C.R. $=2 \cdot 29)$. The group with poor night vision had a much smaller proportion of individuals taking active interest in social groups, and 84 per cent. were described as having narrow interests. Twelve per cent. of the poor group had a history of excessive alcohol consumption, whereas none of the good group had such a

TABLE 3 .

\begin{tabular}{|c|c|c|c|c|c|}
\hline Intelligence grade & $\begin{array}{l}\text { Poor night } \\
\text { vision group } \\
\mathrm{N}=50 \\
\text { (per cent.) }\end{array}$ & $\begin{array}{c}\text { Good night } \\
\text { vision group } \\
N=13 \\
\text { (per cent.) }\end{array}$ & $\begin{array}{l}\text { Difference in } \\
\text { percentage }\end{array}$ & $\begin{array}{l}\text { Standard } \\
\text { error of } \\
\text { difference }\end{array}$ & Critical ratio \\
\hline $\begin{array}{r}\text { V } \\
\text { IV } \\
\text { III } \\
\text { II } \\
\text { I }\end{array}$ & $\begin{array}{r}8 \\
22 \\
40 \\
22 \\
8\end{array}$ & $\begin{array}{c}7 \cdot 69 \\
\overline{15 \cdot 38} \\
46 \cdot 15 \\
30 \cdot 75\end{array}$ & $\begin{array}{r}0 \cdot 31 \\
22 \cdot 00 \\
24 \cdot 62 \\
24 \cdot 15 \\
22 \cdot 76\end{array}$ & $\begin{array}{r}8 \cdot 59 \\
5 \cdot 55 \\
12 \cdot 50 \\
15 \cdot 53 \\
13 \cdot 86\end{array}$ & $\begin{array}{l}0.03 \\
3.75 \\
1.96 \\
1.55 \\
1.64\end{array}$ \\
\hline Mean grade & $3 \cdot 0$ & $2 \cdot 07$ & & & \\
\hline
\end{tabular}


history $(C . R .=2 \cdot 61)$. The percentage of the poor night vision group having normal mental health before the present illness was only 16 per cent. compared with 61.53 per cent. of the good night vision group; the difference is statistically significant $(C . R .=3.04)$. Sixty per cent. of the poor group had a clear predisposition to neurotic illness compared with 23 per cent. of the good night vision group $(C . R .=2 \cdot 6)$. Similarly, a statistically significantly higher proportion had previously had a definite mental illness (16 per cent. and nil respectively) $(C . R .=3.08)$. Thus on the whole the personal history of the group with poor night vision is less satisfactory than that of the group with good night vision.

Personality.-Only 30 per cent. of the poor night vision group had a well-organized stable rersonality compared with 76.92 rer cent. of the good group; the difference is statistically significant (C.R. $=3 \cdot 4)$. Similarly, the percentage with neak, derendent, timorous rersonalities is significantly greater in the poor group (66 rer cent. ccmpared with 23.08 rer cent. C.R. $=3 \cdot 0$ ). Cyclothymic tendencies also occurred in significantly greater frequency in the poor group (52 per cent. compared with 7.69 per cent. C.R. $=3 \cdot 6$ ). Similarly, 22 per cent. of the poor group were regarded as being very anxious and highly strung, whereas none of the good group fell into this category (C.R.=3.7). Obsessional traits occurred in 14 per cent. of the poor night vision group, and in none of the good group $(C . R .=2 \cdot 85)$. There were no significant differences in the proportion of schizoid, hysterical or hypochondriacal traits.

Symptoms and Findings. - In a comparison of 30 items, the following showed statistically significant differences:-

Suicidal tendencies (16 per cent. in poor group, none in good group : C.R.=3.08). Stammer (8 per cent. poor group, nil in good group : C.R. $=2 \cdot 08)$. Poor muscular tone and posture (10 per cent. poor group, nil in good group: C.R. $=2 \cdot 3$ ).

\section{Discussion}

Our results show that the neurotic group performed more poorly on night vision testing than the various normal groups considered. On subdividing the group into diagnostic types it was found that they did not differ significantly from each other on the test but were significantly inferior to the R.A.F. normal group. Within the total neurotic sample we find that the group with low scores differs significantly from the group with high scores in a number of psychiatric traits.

The group of individuals with low night vision scores is associated with a clinically abnormal personality (as shown by general instability, weakness and dependence, cyclothymic tendencies, anxious and highly strung, obsessional traits and narrow interests) a positive family history of neuropathy, previous mental illness or clear disposition to neurosis, or a poor school and work record.

These findings are of particular interest in view of recent work by Slater (1943), who found that the above traits were the best indicators of the neurotic constitution, thus showing that the group of individuals performing poorly on the night vision test are of more marked neurotic constitution than those who did well.

The reason for the poor performance on the night vision test of the markedly neurotic individual is not clear. The possibility that the poor results are due to malingering can be ruled out as a special test for malingering was applied, and only one individual gave a result indicative of malingering. It seems possible that the poor performance of the neurotic group on the test might be due to a defect at the perceptual level and that the neurotic, through possible lack of incentive or other cause would tend to do poorly on a complex perceptual test of this kind. Although an attempt was made to counteract any lack of incentive, it is not completely possible to rule it out as a possible factor. It is, however, difficult to see why lack of incentive should operate in this test and not in the matrices intelligence testa complex perceptual test in which this group performed better than the average.

Kekcheyev et al. (1943) point out that sensitivity of night vision is one of the most fluctuating functions of the human organism and that such factors as fatigue, distension of visceral organs, and strong stimulation of other sense organs may diminish night vision. The same authors found that the effect of conditioned reflexes on night visual acuity may be strong, so that poor night vision may result from any fears associated with darkness. In order to test this possibility the medical records were examined, and it was found that 60 per cent. of the group of men with poor night vision had marked fears of the dark, either in childhood or adult life, whereas only 27.7 per cent. of the good night vision group had similar fears. The difference is statistically significant $(C . R .=2 \cdot 3)$. Thus fear of the dark may in some cases be a factor in the pathogenesis of poor night vision.

Although a number of features such as age, intelligence, neurotic constitution, and certain psychiatric traits were found which show a definite relationship with performance on the test, the precise nature of the defect in the neurotic group has yet to be elucidated.

It is possible that the results do not indicate a specific defect, but a general deficiency which predisposes to the development of neurosis. It would seem that the results support a recent heuristic theory of neurosis postulated by Slater and Slater (1944). This heuristic theory states that the neurotic constitution is predominantly determined by a large number of genes of small effect. The effects of these genes, at least in so far as they are qualitatively similar, may be additive and they become manifest by producing a reduced resistance to some form of environmental stress, and so facilitate the appearance of neurosis. The authors found that neurotics, on the average, had poorer auditory and day-time visual activity than normal control groups. 
A deficiency in such abilities together with other attributes of the neurotic constitution would tend to lower resistance to stress and facilitate the development of neurosis.

\section{Summary}

1. A random sample of 96 neurotic soldiers were tested with the Livingston Rotation Hexagon and were found to be considerably below the normal population in night visual capacity.

2. Dividing the group into neurotic types it was found that they did not differ significantly from each other but were significantly inferior in night vision test score to the R.A.F. normal group.

3. Age and night vision test score showed a significant correlation, older individuals tending to score more poorly on the test.

4. The correlation between intelligence grade and night vision score was insignificant for the group as a whole. The group with good vision scores, however, had significantly greater proportion of individuals above average intelligence than the group with low night vision scores.

5. Suggestion was found to have no significant effect on the score obtained.

6. The group with poor night vision scores was compared with a group obtaining good scores. The poor night vision group had a lower standard of education, poorer work history, narrower interests, greater incidence of alcoholism and previous mental illness, a greater predisposition to neurosis, a higher proportion of weak, dependent, anxious, cyclothymic and obsessional types of personality and a greater incidence of suicidal tendency, stammer and poor muscular tone and posture. There was also a greater incidence of fear of the dark either in child- hood or adult life among individuals with poor night vision scores. In short, the group of individuals with poor night vision scores presented a more marked neurotic picture with greater constitutional predisposition to neurosis.

7. The findings are discussed in relation to a recent heuristic theory of neurosis.

I wish to thank Dr. W. S. Maclay for permission to publish the case material and Air Commodore Livingston for valuable advice.

\section{REFERENCES}

Culpin, M. (1940) in Modern Trends in Opthalmology, Edited by F. Ridley and A. Sorsby, p. 50, London.

Derby, G. S. (1921). J. Amer. med. Ass., 77, 1002.

Duke Elder, W. S. (1938). Text Book of Ophthalmology, London, vol. $1,982$.

Ferree, C. E., Rand, G., and Lewis, E. F. (1935). Arch. Ophth., 13, 212.

Ferree, C. E., and Rand, G. (1938). Ibid., 20, 58.

Harman, N. B. (1941). Brit. med. J., 2, 347.

Harris, L. J. and Abbasy, M. A. (1939). Lancet, 2, 1999.

Holcomb, R. C. (1934). J. Amer. med. Ass., 102, 786.

Jeans, P. C. and Zentmire, Z. (1934). J. Amer. med. Ass., 102, 892.

Kekcheyev, M., Derzhavin, N., and Pilipchuk, S. (1943). War Med., 3, 171.

Lister, A., and Bishop, J. W. (1943). Brit. med. J., $2,325$.

Livingston, P. C., and Bolton, B. (1943). Lancet, 1, 263.

Livingston, P. C. (1942). Brit. J. Surg., 29, 339.

Lythgoe, R. J. (1940). Brit. J. Ophth., 24, 21.

Maitra, M. K., and Harris, L. J. (1937). Lancet, 2, 1009.

Rycroft, B. W. (1942). Brit. med. J., 2, 576.

Schuck, C., and Miller, W. O. (1938). Arch. int. Med., 61, 910.

Slater, E. (1943). J. Neurol. Psychiat., 6, 1.

Slater, E., and Slater, P. (1944). Ibid., 7, 49.

Smith, H. (1921). J. Amer. med. Ass., 77, 1001.

Steadman, B. St. J. (1942). J. roy. Army med. Corps, 78, 14.

Wittkower, E., Rodger, T. F. et al. (1941). Brit. med. J., 2, 571, 2, 607.

Yudkin, J. (1943). Brit. med. J., 1, 633. 